\title{
Daqing Oilfield Liquid Phase Underbalanced Drilling Improving Drilling Speed Evaluation Method
}

\author{
Shibin Li, Penghao Wang, Ligang Zhang \\ Oil and Gas Well Engineering, College of Petroleum Engineering, Northeast Petroleum University, Daqing, China \\ Email: wph616@126.com
}

Received 13 November 2014; accepted 8 December 2014; published 14 January 2015

Copyright (C) 2015 by authors and Scientific Research Publishing Inc.

This work is licensed under the Creative Commons Attribution International License (CC BY). http://creativecommons.org/licenses/by/4.0/ cc) (7) Open Access

\begin{abstract}
Factors affecting the drilling speed are very complex, such as formation factor (layers lithology, depth, porosity and reservoir pressure), fluid density, drilling parameters (bit pressure and speed), drill types, etc. Although liquid phase underbalanced drilling technology is to increase the penetration rate and shorten the drilling cycle, there is no evaluation model currently, so we cannot evaluate which factors can have a greater impact on speed. Based on the establishment of equivalent density and improvement of ROP (Rate of Penetration) calculation model, this paper is about the application of underbalanced drilling technology to improve drilling speed multiple sizes.
\end{abstract}

\section{Keywords}

Liquid Phase under Balanced Drilling, Evaluation, Improving Drilling Speed, Multiple

\section{Introduction}

Compared with conventional drilling technology, underbalanced drilling technology can improve ROP significantly. However, there are no quantitative methods of evaluating how much ROP the application of a certain kind of underbalanced drilling technology can improve. ROP factors include formation factor (layers lithology, depth, porosity and reservoir pressure), fluid density [1], drilling parameters (bit pressure and speed), drill types [2], etc. Evaluation model can be established by analyzing UBD (Underbalanced Drilling) ROP increased by exploring underbalanced drilling technology and the parameters of conventional drilling technology changes, so as to realize UBD improving ROP [3], and furthermore, to provide quantitative data for the early evaluation of adaptation UBD. 


\section{ROP Equation Preferred}

Frequently-used ROP model mainly includes corrected Young ROP equation [4], Moller drilling rate equation, Amoco drilling rate equation, Bingham drilling rate equation, multiple drilling rate equation, etc. One type of these equations is determined by laboratory rock drill and a full-size bench test to establish the drilling rate equation, but it cannot realistically simulate the actual situation in the field, and has little applicability for the prediction of ROP. Another drilling rate equation, whether it is a binary or diverse, is based on site drilling rate, which is restricted to be applicable in a particular area or similar geological conditions, without universal applicability.

Domestic drilling rate calculation equation has been established since the 1960s, by combining the two types of calculation method, doing large-scale and systemic experiments in the laboratory on rock drill, obtaining stratified statistics of drillability pole value of different geological ages, regressing according to a combination of cross-sectional area of the drilling depth of compaction law correction, we can establish a macro-gradient formula which can be used to drill in the area. Then apply the logging data, correct the experiment established ROP, analyze all the factors affecting the penetration rate of the drill, which include press, speed, bit type, hydraulic parameters, drilling performance and other aspects [5]. And establish drillability to form a common drilling rate equation. The equation has broad applicability, the error rate of which is less than $10 \%$ compared with the actual drilling.

Universal drilling rate equation [6]:

$$
V=\frac{131.27}{14.273^{A} \cdot 60^{B} \cdot 9^{C} \cdot \mathrm{e}^{1.15 D}} W^{A} \cdot R^{B} \cdot N^{C} \cdot \mathrm{e}^{D \cdot \rho}
$$

Symbol description:

$V$ : Rate of penetration, $\mathrm{m} / \mathrm{h}$;

$W$ : Than the weight on bit, t/in;

$R$ : Speed, r/min;

$N$ : Than water power, $\mathrm{kw} / \mathrm{cm}^{2}$;

$A=0.5366+0.1993 K_{d}$ : Index weight on bit;

$B=0.9250-0.0375 K_{d}:$ Index of the revolution;

$C=0.7011-0.05682 K_{d}:$ Formation water index;

$D=0.97673 K_{d}-7.2703$ : Drilling fluid density coefficient;

$K_{d}$ : Coefficient of formation drillability.

1) Then (than) bit pressure is calculated as:

$$
W=\frac{4 P_{Z}}{\pi D^{2}}
$$

Symbol description:

$P_{\mathrm{Z}}$ : Bit pressure, $\mathrm{kN}$;

$D$ : The bit diameter, $\mathrm{cm}$.

2) Drill bit computing power than water formula:

$$
N=\frac{4 N_{b}}{\pi D^{2}}
$$

Symbol description:

$N_{b}$ : Bit of water power: $\mathrm{kw} / \mathrm{cm}^{2}$.

3) Drill water power calculation formula:

$$
N_{b}=\frac{\rho Q^{3}}{2 C^{2} A_{0}^{2}}
$$

Symbol description:

$\rho$ : Drilling fluid density, $\mathrm{g} / \mathrm{cm}^{3}$;

$Q$ : Mud displacement, L/s;

$C$ : Nozzle flow coefficient (a fixed constant); 
$A_{0}$ : The equivalent nozzle area, $\mathrm{m}^{2}$.

4) Equation (4) into (3) to obtain:

$$
N=2 \cdot \frac{\rho Q^{3}}{\pi C^{2} A_{0}^{2} D^{2}}
$$

\section{Establish the Effect of Liquid Underbalanced Drilling Speed Evaluation Methods}

The common equation used to calculate the liquid underbalanced drilling speed, if $V_{q}$ is used to represent underbalanced drilling penetration rate, you can Equation (1) transform as follows:

$$
V_{q}=\frac{131.27}{14.273^{A} \cdot 60^{B} \cdot 9^{C} \cdot \mathrm{e}^{1.15 D}} W_{q}^{A} \cdot R_{B}^{B} \cdot N_{q}^{C} \cdot \mathrm{e}^{D \cdot \rho_{q}}
$$

Symbol description:

$V_{q}$ : Under the underbalance of penetration, $\mathrm{m} / \mathrm{h}$;

$W_{q}:$ Underbalanced conditions than bit pressure, t/in;

$R_{q}:$ Speed, $\mathrm{r} / \mathrm{min}$

$N_{q}$ : Underbalanced than water power, $\mathrm{kw} / \mathrm{cm}^{2}$.

When underbalanced than water power [7]:

$$
N_{q}=2 \cdot \frac{\rho_{q} Q_{q}^{3}}{\pi C^{2} A_{0}^{2} D^{2}}
$$

Symbol description:

$\rho_{q}$ : Underbalance drilling the actual mud density required, $\mathrm{g} / \mathrm{cm}^{3}$;

$Q_{q}$ : Underbalanced mud displacement, L/s.

Evaluation of the effect of underbalanced drilling speed can be balanced drilling conditions due to changes in the parameters of the liquid through discussion deduced speed factor formula [8].

Set speed multiples, the speed factor is calculated as:

$$
r=\frac{V_{q}}{V}
$$

Daqing oilfield eastern changyuan carried out in recent years, dozens of wells in liquid underbalanced drilling, drill press, speed, drilling fluid displacement [9], borehole size, the corresponding section of rock wells can be drilled and used drill type are the same as compared to conventional drilling.

Therefore, $W_{q}=W, R_{q}=R, Q_{q}=Q[10]$ and therefore Equations (1) (6) into (8) can be calculated as a multiple of the speed obtained:

$$
r=\left(\frac{N_{q}}{N}\right)^{C} \cdot \mathrm{e}^{D \cdot\left(\rho_{q}-\rho\right)}
$$

The (5) (7) into Equation (9), a multiple speed final formula is obtained:

$$
r=\left(\frac{\rho_{q}}{\rho}\right)^{C} \cdot \mathrm{e}^{D \cdot\left(\rho_{q}-\rho\right)}
$$

Before drilling, through knowing formation of designs can be drilled hole section coefficient $K_{d}$, conventional drilling fluid density adjacent wells and underbalanced drilling fluid density design, and applying Formula (10) can calculate speed multiple theory. Effect evaluation of accelerating was carried out by selecting 8 underbalanced wells, the concrete data were shown in Table 1.

As can be seen from Table 1, the errors of the calculation speed and the actual speed multiples, and in engineering practice such errors are acceptable.

\section{Conclusions}

1) By comparing the actual drilling data validation, evaluation methods of underbalanced drilling speed in this 
Table 1. The eastern part of the refracture underbalanced well speed-up effect evaluation.

\begin{tabular}{|c|c|c|c|c|c|c|c|c|c|}
\hline Well No. & $\begin{array}{c}\text { Underbalance } \\
\text { interval } \\
\text { m }\end{array}$ & $\begin{array}{l}\text { Underbalanced } \\
\text { drilling fluid } \\
\text { density } \\
\mathrm{g} / \mathrm{cm}^{3}\end{array}$ & $\begin{array}{l}\text { Adjoining } \\
\text { well } \\
\text { conventional } \\
\text { drilling fluid } \\
\text { density } \mathrm{g} / \mathrm{cm}^{3}\end{array}$ & $\begin{array}{c}\text { Coefficient } \\
\text { of } \\
\text { formation } \\
\text { drillability } \\
K_{d}\end{array}$ & $\begin{array}{c}\text { Calculate } \\
\text { multiples } \\
r\end{array}$ & $\begin{array}{l}\text { Adjoining well } \\
\text { conventional } \\
\text { actual drilling } \\
\text { rate of } \\
\text { penetration } \mathrm{m} / \mathrm{h}\end{array}$ & $\begin{array}{l}\text { Under-balanced } \\
\text { drilling the } \\
\text { actual rate of } \\
\text { penetration } \\
\mathrm{m} / \mathrm{h}\end{array}$ & $\begin{array}{l}\text { The } \\
\text { actual } \\
\text { ratio }\end{array}$ & $\begin{array}{l}\text { Calculate } \\
\text { multiples } \\
\text { ratio and } \\
\text { the actual } \\
\text { error rate }\end{array}$ \\
\hline SongShen101\# & $2974-3480$ & 0.92 & 1.15 & 5.24 & 1.77 & 1.16 & 2.27 & 1.95 & $9.2 \%$ \\
\hline WeiShen5\# & $3087-3610$ & 0.94 & 1.15 & 5.16 & 1.78 & 1.25 & 2.46 & 1.97 & $9.6 \%$ \\
\hline WeiShen501\# & 3098 - 3457 & 0.92 & 1.15 & 5.67 & 1.76 & 1.33 & 2.60 & 1.95 & $9.7 \%$ \\
\hline ZhaoShen11\# & $3170-3410$ & 0,93 & 1.10 & 5.48 & 1.80 & 1.02 & 1.92 & 1.91 & $5.8 \%$ \\
\hline XuShen1\# & 3187 - 3960 & 0.94 & 1.12 & 5.84 & 1.78 & 1.56 & 2.88 & 1.84 & $3.3 \%$ \\
\hline XuShen3\# & $3625-4763$ & 0.92 & 1.10 & 6.23 & 1.81 & 1.14 & 1.95 & 1.71 & $5.9 \%$ \\
\hline XuShen5\# & $3338-4057$ & 0.92 & 1.15 & 5.89 & 1.77 & 1.04 & 1.88 & 1.82 & $2.7 \%$ \\
\hline
\end{tabular}

paper can be used in underbalanced drilling east of Daqing Changyuan, and the accuracy of speed is relatively high;

2) For the wells to use liquid underbalanced drilling technology, we can use underbalanced speed theoretical models and evaluation methods for pre-underbalanced drilling technology. We can calculate the speed factor theory, and calculate the application of underbalanced drilling technology to shorten the drilling cycle and the resulting economic profits, quantitatively evaluating the speeding effects of underbalanced drilling technology.

\section{Funding}

The national natural science foundation of China "based on stress-seepage-much damage field coupling of reservoir and fracture mechanism of water filter research (51274069)”.

\section{References}

[1] Qu, Y.Z., Sun, J.S. and Su, Y.N. (2006) Rapid Advances in Drilling Fluid Technology. Journal of Drilling Fluid and Completion Fluid, 23, 68-70.

[2] Sugden, S. (1922) Determination of Surface Tension from the Maximum Pressure in Bubbles. Journal of the Chemical Society, 121, 858-866. http://dx.doi.org/10.1039/ct9222100858

[3] Sun, J.S., Yang, Y.P. and An, S.M. (2009) Improve the Penetration Rate of Drilling Fluid Theory and Technology Research. Journal of Drilling Fluid and Completion Fluid, 26, 12-15.

[4] Li, Z.G. (2011) The Best Method of Optimization Design of Rate of Penetration. Journal of Drilling Technology, 34, 14-16.

[5] Fan, X.Y., et al. (2007) Based on Seismic Data of Drilling Rate Prediction Research. Journal of Daqing Petroleum Geology and Development, 26, 121-124.

[6] Gao, C.L. and He, Y.R. (1992) Use the Multiple Regression Analysis Method to Establish Deep Well Drilling Rate Equation. Journal of Drilling Technology, 20, 30-32.

[7] Grocock, F.B., Sinor, L.A., et al. (1994) Innovative Additives Can Increase the Drilling Rates of Water-Based Muds. Society of Petroleum Engineers 28708.

[8] Li, H.Q., Gao, C.L. and Ren, Y.X. (1995) Pressure Difference on the Influence Law of Rate of Penetration. Journal of Drilling Technology, 19, 10-15.

[9] Lin, Y.H., Bao, Y.Y., Liang, Z., et al. (2004) Oil Drilling Mechanical Drilling Rate Prediction Research Progress. Oil Drilling Technology, 32, 10-13.

[10] William, D., Ken, D., et al. (2005) New Water-Based Mud Balances High-Performance Drilling and Environmental. Society of Petroleum Engineers 92367. 
Scientific Research Publishing (SCIRP) is one of the largest Open Access journal publishers. It is currently publishing more than 200 open access, online, peer-reviewed journals covering a wide range of academic disciplines. SCIRP serves the worldwide academic communities and contributes to the progress and application of science with its publication.

Other selected journals from SCIRP are listed as below. Submit your manuscript to us via either submit@scirp.org or Online Submission Portal.
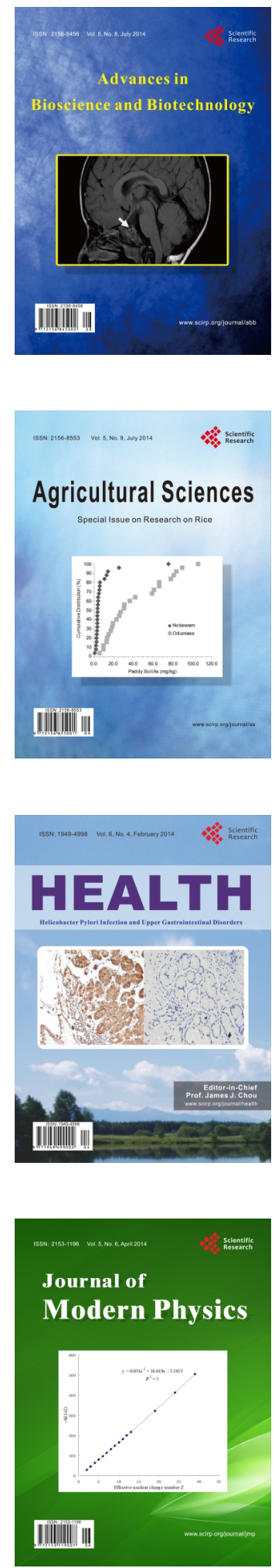
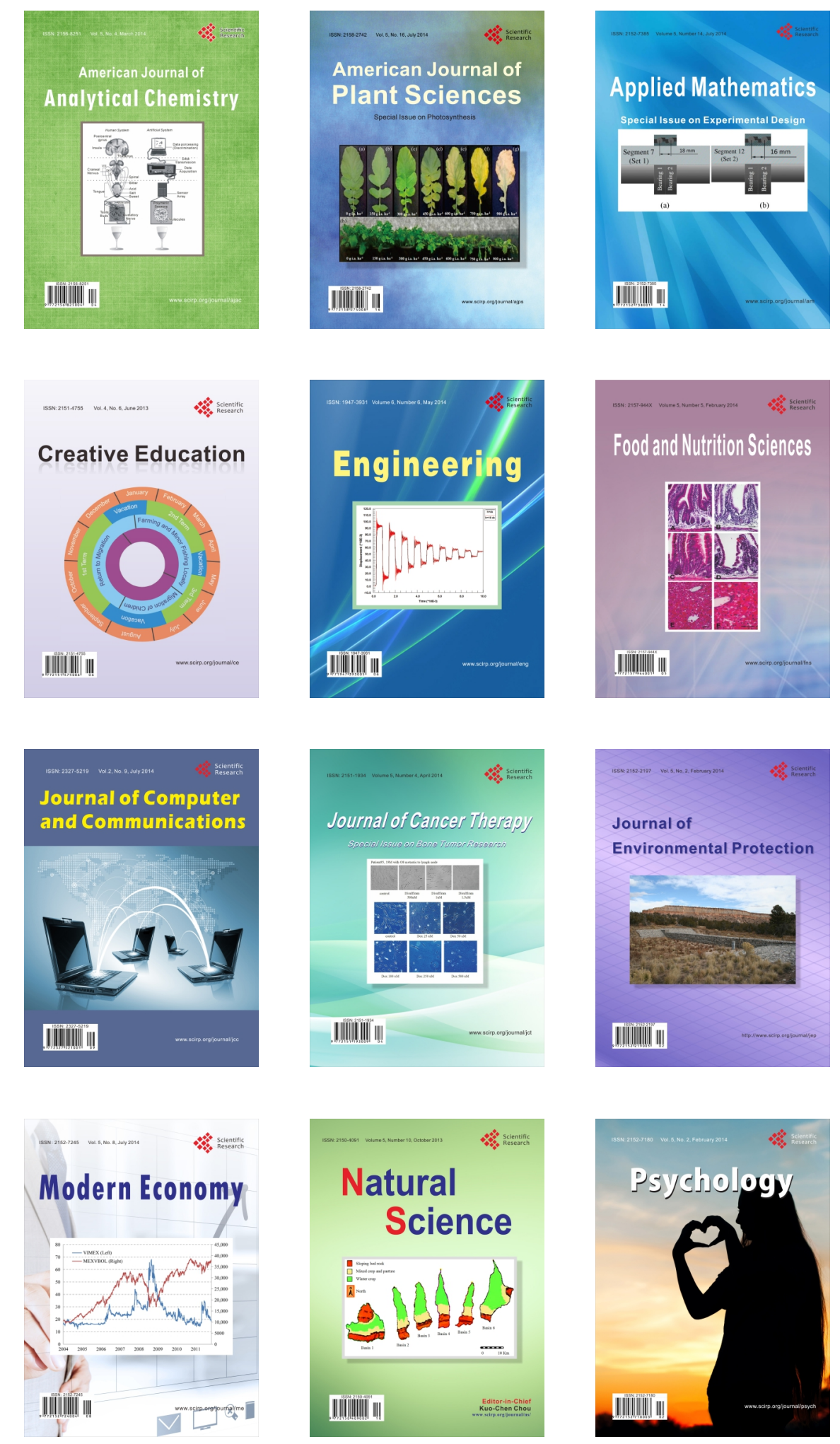